Original article

\title{
Asimetrik Bilginin BES Katılımcıları Üzerine Etkisi: İstanbul İli Örneği ${ }^{1}$
}

Effects of Asymetrical Knowledge over Private Retirement Schemes Participiants: The Case Of Istanbul Province

\author{
Hasan Alp Özel (ㅁ) a, " \& Esra Kara (ํ) a \\ a Department of Actuary and Risk Management, Institute of Social Sciences, Karabük University, Karabük, Turkey
}

\begin{abstract}
Özet
Sigortacılık sektöründe son yıllarda önemli bir yer edinen Bireysel Emeklilik Sistemi (BES) aynı zamanda sektöre yeni bir ivme kazandırmıştır. Yapılan araştırmada tüketicilere BES'de asimetrik bilgi olgusunun var olup olmadığı sorulmuş ve alınan cevaplar doğrultusunda sistemden ayrılma nedenleri belirlenmeye çalışılmıştır.

Asimetrik Bilgi, alıcı ve satıcı arasındaki bilgi simetrisinin bozulmasından kaynaklanan bir problemi ifade etmektedir. Çalışma ile BES'e dahil olan ve daha sonra sistemden ayrılma kararı alan bireylerin bu kararı almalarında etkili olan faktörün ne kadar asimetrik bilgi olgusuna dayandığını ortaya koymak amaçlanmıştır. Bu çalışma ile belirlenecek olgular doğrultusunda sistem üzerinde gerekli düzenlemelerin yapılması ve bireysel emeklilik sisteminin tüketiciye tam ve doğru anlatılması bu şekilde de sisteme güven ve katılımın artması açısından önemlilik arz etmektedir.
\end{abstract}

Anahtar Kelimeler: Bireysel Emeklilik Sistemi, Asimetrik Bilgi, Karar Verme.

\begin{abstract}
The Private Pension System (BES), which has gained an important place in the insurance sector in recent years, has also brought a new momentum to the sector. In the research conducted, the consumers were asked whether an asymmetric information phenomenon about BES exists and the reasons for leaving the system were tried to be determined in line with the answers received. Asymmetric Information refers to a problem caused by the deterioration of the information symmetry between the buyer and seller. The study aims to reveal how much asymmetric information factor is included among other factors that are effective in making this decision of individuals who are included in BES and then decided to leave the system. In line with the facts to be determined with this study, making necessary arrangements on the system and explaining the private pension system to the consumer fully and correctly are important in terms of increasing trust and participation in the system.
\end{abstract}

Keywords: Private Pension System, Asymmetric Information, Decision Making.

Received: 26 May 2020 * Accepted: 29 June $2020 \quad * \quad$ DOI: https://doi.org/10.29329/ijiasos.2020.260.2

\footnotetext{
* Corresponding author:

${ }^{1}$ Bu çalışma Doç. Dr Hasan Alp ÖZEL'in danışmanlığında Esra KARA tarafından yapılan Bireysel Emeklilik ve Asimetrik Bilgi: Türkiye Örneği isimli Yüksek Lisans tez çalışmasından türetilmiştir.
}

Hasan Alp Özel, Department of Actuary and Risk Management, Institute of Social Sciences, Karabük University, Karabük, Turkey. Email:alpalp78@hotmail.com 


\section{GíRiş}

BES, çalışanların aktif çalışma hayatları boyunca birikimlerini "uzun vadeli yatırıma" çevirebilmeleri ve emekli oldukları zamanda da çalışırken sahip oldukları yaşam standartlarını devam ettirebilecekleri düzeyde gelire sahip olmalarını sağlamak amacıyla oluşturulmuş bir sistemdir (www.egm.org.tr). Pazardaki alıcı ve satıcının ticarete konu olan mal hakkında farklı bilgilere sahip olmasını Akerlof, "Limon Piyasası Modeli” olarak tanımlamıştır. Piyasadaki bilgi farklılığı asimetrik bilgi sorununu da beraberinde getirmektedir (Varian, 1993: 603). Akerlof para piyasaları için geçerli olan Gresham Kanunu'nun piyasanın genelinde de uygulanabileceğini savunmuştur. Akernof'un ikinci el araba piyasalarında asimetrik bilgi olduğu varsayımı altında oluşturduğu limon piyasası modeline göre kötü arabalar "kötü para", kaliteli arabalar ise "iyi para" ile özdeş tutulmaktadır (Akerlof, 1970: 489-490).

Akerlof, alıcılarla ve satıcılar arasında asimetrik bilginin malları hakkında daha fazla bilgiye sahip satıcıların, fırsatçı bir biçimde düşük kaliteli malları alııılara daha yüksek fiyatlara satmalarına olanak verdiğini ifade etmektedir. Benzer şekilde kaliteli ürün üreticileri bu süreçten etkilenmektedir. Ancak bilginin eksik olması, bu tür ürünlerin piyasada olması, gereken değerin altında bir fiyat seviyesinin oluşmasına neden olmaktadır. Stiglitz ve Weiss (1981)* bu düşünceyi kredi piyasasına uyarlamıştır. Bu durumda "alıcılar" borç verenler ve "satıcılar" da kredi talebi olanlardır. Burada borcu alacak olan ödeme gücü hakkında tam bilgiye sahip iken borç veren bu tür bir bilgiye sahip değildir. Bu nedenle de borç verenler bilgi dezavantajlarının farkında olarak borcu alanlara rasyonel bir şüphecilikle yaklaşacaktır (Fazzari, 1981: 393-410). Spence (1973) akerlof ve Stiglitz' e benzer sonuçlar bulmuştur ${ }^{\dagger}$. Varian (1978), Akerlof'un modelinde bazı değişikliler yaparak asimetrik bilginin ters seçim ve ahlaki tehlike sorunlarını da beraberinde getireceğini savunmuştur.

\section{ARAŞTIRMANIN MODELİ VE HIPOTEZLERİ}

Çalışmada İstanbul ilinde farklı hizmet sektörlerinde çalışan, BES içinde yer alan ve belli bir süreden sonra BES'den ayrılan bireyler örneklemi oluşturmaktadır. Tutarsız olan anketler elenmiş ve toplamda 350 anket üzerinde veri girişi yapılmıştır. Çalışmada geliştirilen hipotezler Tablo 1'de verilmiştir.

\footnotetext{
*Ayrıntılı bilgi için bkz: Joseph E. Stiglitz, Andrew Weiss, “Credit Rationing in Markets with Inperfect Information”, The American Economic Review, Vol. 71, No. 3, 1981, pp. 393-410.

† Ayrıntılı bilgi için bkz: Spence, Michael (1973). “Job Market Signaling”. Quarterly Journal of Economics. 87 (3): $355-374$.
} 
Tablo 1. Araştırmanın Hipotezleri

\begin{tabular}{|l|l|}
\hline $\mathbf{H}$ & Hipotez \\
\hline $\begin{array}{l}\mathrm{H}_{1} \\
\text { Ana hipotez }\end{array}$ & Asimetrik bilgi varlığı ile BES'e dâhil olma durumu istatistik anlamlı ilişkilidir. \\
\hline $\begin{array}{l}\mathrm{H}_{2} \\
\text { Alt hipotez }\end{array}$ & $\begin{array}{l}\text { BES'e dâhil olma durumu açısından cinsiyet, yaş, medeni durum, eğitim düzeyi, meslek, } \\
\text { gelir düzeyi ve asimetrik bilgi durumu için anlamlı farklılık vardır. }\end{array}$ \\
\hline $\begin{array}{l}\mathrm{H}_{3} \\
\text { Alt hipotez }\end{array}$ & $\begin{array}{l}\text { BES'e dâhil olma durumu ile cinsiyet, yaş, medeni durum, eğitim düzeyi,meslek, gelir } \\
\text { düzeyi arasında istatistik anlamlı ilişki vardır. }\end{array}$ \\
\hline
\end{tabular}

Son yıllarda örneklem hacminin belirlenmesinde, "yapılacak olan analiz için en az kaç örneklem gerekli” olduğunu belirten Güç analizi kullanılmaktadır. Kısaca, güç analizi yapılacak her analiz çeşidi için en az kaç örneklem gerektiğini ortaya koymaktadır. Bu çalışmada hem grup farklılığı hem de ilişki analizi yapılacaktır. Bu çalışmada Güç (power) analiz G*POWER 3.1 sürümü ile gerçekleştirilmiştir. İstatistik anlamlılık $\alpha=0.05$ alınmıştır.

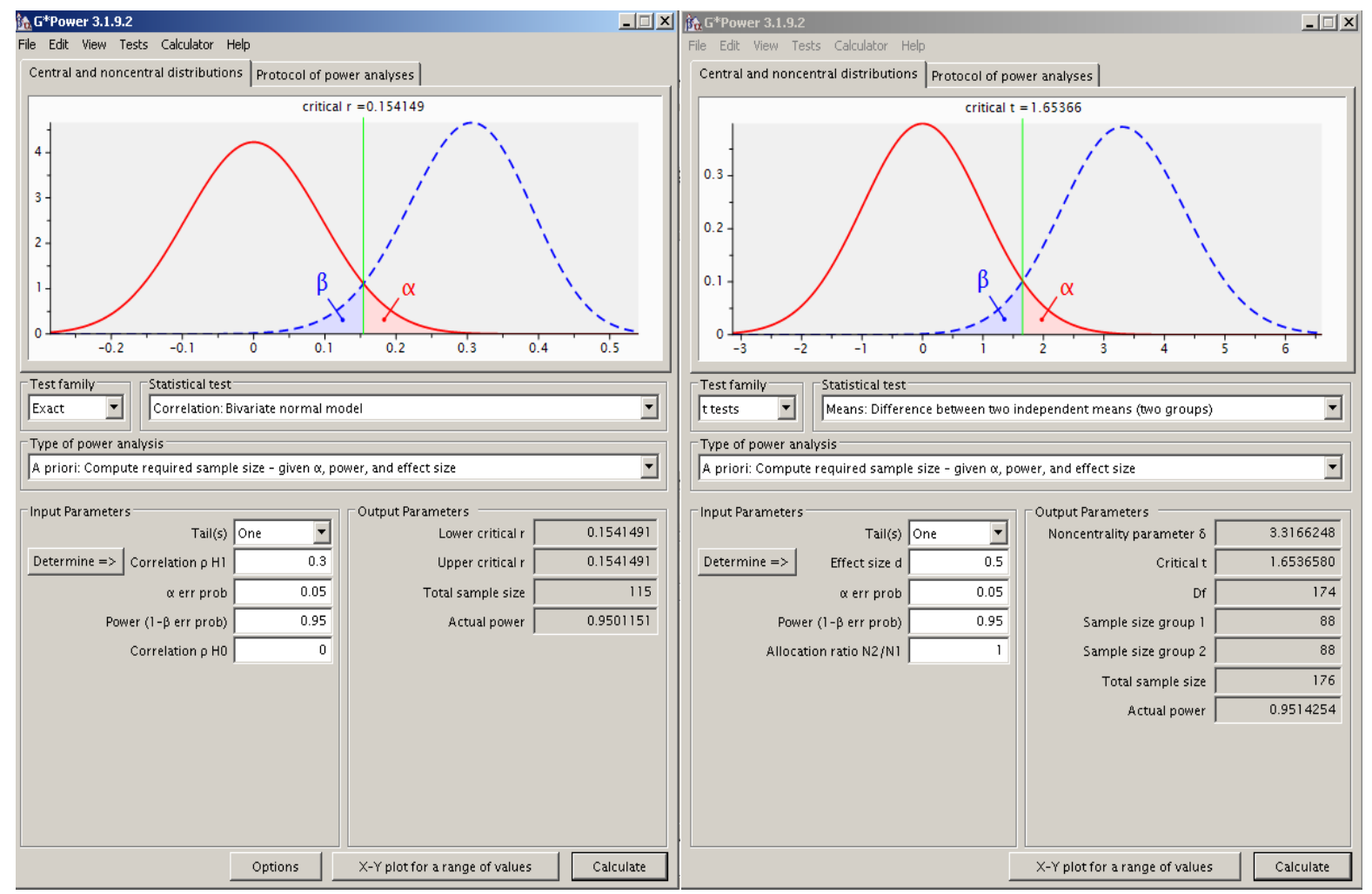

Şekil 1: Korelasyon ve Grup Farklılığı için Güç analizi sonuçları ekran çıktısı

Güç analizi sonucunda en az 115 örneklem ile çalış1lması durumunda çalışmanın geçerliliği belirlenmiştir. Bu çalışmada 350 örneklem kullanılmış, yapılacak analizlerin güvenilir olacağı ortaya konulmuştur. Güç analizi sonucunda grup farklılığı analizlerinde en az 176 örneklem ile çalışılması durumunda çalışmanın geçerliliği belirlenmiştir. Bu çalışmada 350 örneklem kullanılmış, yapılacak analizlerin güvenilir olacağı ortaya konulmuştur. 
Yapılan anket çalışması "deneysel olmayan nicel araştırma" tasarımındadır ve uygulanma biçimine göre tarama yöntemi kullanılmıştır. Çalışmada, örneklemden verilerin toplanması açısından "survey modeli (saha taraması)" kullanılmıştır. Saha taraması modelinde ise katılımcıların görüşlerinin yazılı şekilde alındığı bir veri toplama yöntemi olan anket yöntemi tercih edilmiştir. Çalışmada kullanılan anket, geniş bir literatür taraması neticesinde konuya uygun hazırlanmış bir ölçek bulunamaması sonucunda tarafımızdan geliştirilmiştir.

. Çalışmada kullanılan ölçekten elde edilen verilerin analizi IBM SPSS 24.0 programı kullanılarak yapılmıştır. Birinci aşamada demografik bilgilerin bulunmuş olduğu genel bilgilere ilişkin frekans dağılımları sunulmaktadır. İkinci aşamada, çalışmada kullanılan anketin güvenilirlik analizleri gerçekleştirilmiştir. Hipotezleri test edebilmek açısından Kolmogorov-Simirnov ve Shapiro-Wilk normallik sınamaları yapılmıştır. Verilerin dağılımları normal dağılıma uymadığı için grup farklılıkları sınamasında her bir ikili grup için Mann-Whitney-U testi ve üçlü ve fazla grup için de Kruskal Wallis testleri yapılmıştır. Gruplar arasındaki farkların kaynağını tespit edebilmek için ortalama sıra (mean rank) değerleri incelenmiştir. Ölçeğin dağılımında normal dağılıma uyum sağlanamadığından ilişki analizlerinin sınanmasında Kendall's tau_b korelasyon analizinden faydalanılmıştır.

\section{ARAŞTIRMANIN BULGULARI VE YORUMLARI}

Tablo 2'den de görülebileceği üzere ele alınan bütün güvenilirlik kriterleri \%70 değerini geçmiştir. Dolayısıyla anket kendi içerisinde tutarlıdır. Bu bağlamda anketin incelenmesi gerçek değerleri yansıtmaktadır.

Tablo 2. Anketin Güvenilirlik Analizleri Sonuçları

\begin{tabular}{|l|l|}
\hline & Anketin Güvenirlilik Sonuçları \\
\hline Cronbach_Alpha & 0.882 \\
\hline Split & $0.881-0.883$ \\
\hline Parelel & 0.883 \\
\hline Strict & 0.882 \\
\hline
\end{tabular}

Anket katılımcıları için oluşturulan sıklık tablosu verileri Tablo 3, Tablo 4, Tablo 5, Tablo 6, tablo 7 ve Tablo 8'de verilmiştir.

Tablo 3. Gelir Düzeyi Sıklık Yüzde Tablosu

\begin{tabular}{|l|l|l|l|}
\hline \multicolumn{2}{|l|}{ Değiişkenler } & Sıklık & Yüzde \\
\hline \multirow{3}{*}{$\begin{array}{l}\text { Gelir } \\
\text { Düzeyi }\end{array}$} & $2000-2500$ & 100 & 28,6 \\
\cline { 2 - 4 } & $3000-3500$ & 100 & 28,6 \\
\cline { 2 - 4 } & $4000-4500$ & 63 & 18,0 \\
\cline { 2 - 4 } & 5000 ve üstü & 86 & 24,6 \\
\hline
\end{tabular}


Tablo 4. Zorunlu Bireysel Emeklilik Sistemi Bilgilendirilmesi İle İlgili Soruların Sıklık Yüzde Tablosu

\begin{tabular}{|c|c|c|c|}
\hline \multicolumn{2}{|l|}{ Değişkenler } & Sıklık & Yüzde \\
\hline \multirow{5}{*}{ Dâhil Olurken } & Araştırıp Bilgi Edindim & 81 & 23,1 \\
\hline & Yakın Çevre & 45 & 12,9 \\
\hline & Müşteri Danışmanını Dinledim & 76 & 21,7 \\
\hline & Zorunlu BES'e Dâhilim & 57 & 16,3 \\
\hline & Dâhil Değilim & 91 & 26,0 \\
\hline \multirow{3}{*}{ Yeteri Kadar Bilgilendirme } & Evet & 48 & 13,7 \\
\hline & Hayır & 171 & 48,9 \\
\hline & Kismen & 131 & 37,4 \\
\hline \multirow[b]{2}{*}{ Asimetrik Bilgi } & Evet, mevcut & 251 & 71,7 \\
\hline & Hayır, mevcut değil & 99 & 28,3 \\
\hline
\end{tabular}

Tablo 5. Demografik Bilgilerin Sıklık Dağılım Tablosu

\begin{tabular}{|c|c|c|c|}
\hline \multicolumn{2}{|l|}{ Değişkenler } & \multirow{2}{*}{$\begin{array}{c}\text { Siklık } \\
167\end{array}$} & \multirow{2}{*}{$\begin{array}{c}\text { Yüzde } \\
47,7\end{array}$} \\
\hline Cinsiyet & Erkek & & \\
\hline & Kadın & 183 & 52,3 \\
\hline \multirow{6}{*}{ Yaş } & 18-24 Yaş & 49 & 14,0 \\
\hline & 25-30 Yaş & 106 & 30,3 \\
\hline & 31-35 Yaş & 76 & 21,7 \\
\hline & 36-40 Yaş & 55 & 15,7 \\
\hline & 41-45 Yaş & 41 & 11,7 \\
\hline & 46 ve üstü & 23 & 6,6 \\
\hline \multirow{3}{*}{ Medeni Durum } & Evli & 170 & 48,6 \\
\hline & Bekâr & 158 & 45,1 \\
\hline & Boşanmış & 22 & 6,3 \\
\hline \multirow{7}{*}{ Eğitim Düzeyi } & İlkokul & 18 & 5,1 \\
\hline & Ortaokul & 13 & 3,7 \\
\hline & Lise & 67 & 19,1 \\
\hline & Ön lisans & 53 & 15,1 \\
\hline & Lisans & 140 & 40,0 \\
\hline & Yüksek lisans & 41 & 11,7 \\
\hline & Doktora & 18 & 5,1 \\
\hline \multirow{7}{*}{ Meslek } & İşçi & 87 & 24,9 \\
\hline & Öğretmen & 86 & 24,6 \\
\hline & Memur & 15 & 4,3 \\
\hline & Bankacı & 4 & 1,1 \\
\hline & Sigortac1 & 4 & 1,1 \\
\hline & Yönetici & 21 & 6,0 \\
\hline & Diğer & 133 & 38,0 \\
\hline
\end{tabular}


Tablo 6. Zorunlu Bireysel Emeklilik Sistemi İle İlgili Soruların Sıklık Yüzde Tablosu

\begin{tabular}{|c|c|c|c|}
\hline \multicolumn{2}{|l|}{ Değişkenler } & Siklık & Yüzde \\
\hline \multirow{5}{*}{ Anlamlandırma } & Tasarruf Aracı & 79 & 22,6 \\
\hline & Geleceğin Güvencesi & 96 & 27,4 \\
\hline & Emekliliğe Maddi Açıdan Katk1 & 78 & 22,3 \\
\hline & $\begin{array}{l}\text { Kendi Başıma Tasarruf Yapamadığım için } \\
\text { Gerekli }\end{array}$ & 40 & 11,4 \\
\hline & Gereksiz Olduğunu Düşünüyorum & 57 & 16,3 \\
\hline \multirow{3}{*}{$\begin{array}{l}\text { Zorunlu Bireysel Emeklilik } \\
\text { Sistemi }\end{array}$} & Doğru & 85 & 24,3 \\
\hline & Yanlış & 179 & 51,1 \\
\hline & Çekimser & 86 & 24,6 \\
\hline
\end{tabular}

Tablo 7. Sosyal Güvenlikle İlgili Soruların Sıklık Dağılım Tablosu

\begin{tabular}{|l|l|c|c|}
\hline \multicolumn{2}{|l|}{ Değişkenler } & Sıklık & Yüzde \\
\hline \multirow{4}{*}{ Sosyal Güvenlik } & SGK & 259 & 74,0 \\
\cline { 2 - 4 } & BAĞ - KUR & 19 & 5,4 \\
\cline { 2 - 4 } & Emekli Sandı̆̆ı & 72 & 20,6 \\
\hline \multirow{4}{*}{ Sistem Bilgi Düzeyi } & Evet, bilgi sahibiyim & 222 & 63,4 \\
\cline { 2 - 4 } & Kismen bilgi sahibiyim & 114 & 32,6 \\
\cline { 2 - 4 } & Hayır, bilgi sahibi değilim & 14 & 4,0 \\
\hline \multirow{5}{*}{ Etkili Unsur } & Evet & 238 & 68,0 \\
\cline { 2 - 4 } & Hayır & 112 & 32,0 \\
\hline \multirow{5}{*}{ Avantajları } & Iletişim Araçları & 112 & 32,0 \\
\cline { 2 - 4 } & Sigortacılık Kurumları & 90 & 25,7 \\
\cline { 2 - 4 } & Yakın çevre & 94 & 26,9 \\
\cline { 2 - 4 } & Diğer & 54 & 15,4 \\
\hline \multirow{3}{*}{ Sisteme Dâhiliyet } & Biliyorum & 223 & 63,7 \\
\cline { 2 - 4 } & Bilmiyorum & 40 & 11,4 \\
\cline { 2 - 4 } & Kararsızım & 87 & 24,9 \\
\hline & Evet & 211 & 60,3 \\
\cline { 2 - 4 } & Sistemden Ayrıldım & 139 & 39,7 \\
\hline
\end{tabular}


Tablo 8. Zorunlu Bireysel Emeklilik Sistemindeki Soruların Sıklık Yüzde Tablosu

\begin{tabular}{|c|c|c|c|}
\hline \multicolumn{2}{|l|}{ Değiş̧kenler } & Sıklık & Yüzde \\
\hline \multirow{4}{*}{ Tutarlılık } & Evet & 83 & 23,7 \\
\hline & Hayır & 122 & 34,9 \\
\hline & Kararsızım & 99 & 28,3 \\
\hline & Dâhil Değilim & 46 & 13,1 \\
\hline \multirow{3}{*}{ Etkileme } & Evet & 97 & 27,7 \\
\hline & Hayır & 84 & 24,0 \\
\hline & Kismen & 169 & 48,3 \\
\hline \multirow{3}{*}{ Yaşanan Sıkıntılar } & Eksik Bilgi Aktarımı & 129 & 36,9 \\
\hline & Müşterilerini Tanımamaları & 49 & 14,0 \\
\hline & Sürekli Olarak Satış Yapmaya Calıșmaları & 172 & 49,1 \\
\hline
\end{tabular}

İlk aşamada analizlerde hangi yöntemlerin kullanılmasının uygunluğuna karar verebilmek için anket sorularına yönelik normallik testleri uygulanmıştır. Hipotez testlerinde hangi yöntemin kullanılması gerektiği normal dağılımın sağlanmasına bağlı olarak değişecektir. Bu nedenle SPSS programı içinde yer alan Kolmogorov-Smirnov ve Shapiro-Wilk normallik testleri uygulanmıştır.

Tablo 9. Normallik sınaması sonuçları

\begin{tabular}{|l|c|c|c|c|c|c|}
\hline \multirow{2}{*}{} & \multicolumn{3}{|c|}{ Kolmogorov-Smirnov } & \multicolumn{3}{c|}{ Shapiro-Wilk } \\
\cline { 2 - 7 } & İstatistik & s.d. & p & İstatistik & s.d. & p \\
\hline Cinsiyet & .353 & 350 & .000 & .636 & 350 & .000 \\
\hline Yaş & .200 & 350 & .000 & .911 & 350 & .000 \\
\hline Medenidu & .314 & 350 & .000 & .737 & 350 & .000 \\
\hline Ĕ̈itimdü & .241 & 350 & .000 & .915 & 350 & .000 \\
\hline Meslek & .274 & 350 & .000 & .751 & 350 & .000 \\
\hline Gelirdüz & .207 & 350 & .000 & .843 & 350 & .000 \\
\hline Sosyalgü & .456 & 350 & .000 & .562 & 350 & .000 \\
\hline Sistembi & .397 & 350 & .000 & .665 & 350 & .000 \\
\hline Gereklil & .433 & 350 & .000 & .588 & 350 & .000 \\
\hline Sistemed & .394 & 350 & .000 & .621 & 350 & .000 \\
\hline Etkiliun & .200 & 350 & .000 & .854 & 350 & .000 \\
\hline Anlamlan & .199 & 350 & .000 & .881 & 350 & .000 \\
\hline Avatajla & .399 & 350 & .000 & .651 & 350 & .000 \\
\hline Zorunlub & .256 & 350 & .000 & .806 & 350 & .000 \\
\hline Dâhilolu & .158 & 350 & .000 & .865 & 350 & .000 \\
\hline Bilgilen & .263 & 350 & .000 & .787 & 350 & .000 \\
\hline Asimetri & .452 & 350 & .000 & .564 & 350 & .000 \\
\hline Tutarlıl & .210 & 350 & .000 & .874 & 350 & .000 \\
\hline Etkileme & .308 & 350 & .000 & .750 & 350 & .000 \\
\hline Yaşanans & .321 & 350 & .000 & .712 & 350 & .000 \\
\hline
\end{tabular}


Normallik testleri $\mathrm{p}<0.05$ olduğundan normal dağılımın sağlanmadığını belirten $\mathrm{H}_{1}$ hipotezi kabul edilir. Bu durumda grup farklılığı analizlerinde non-parametrik yöntemler kullanılacaktır. Yani; ikili grup için t testi, 2 den fazla grup için ANOVA testi artık uygunluk göstermeyecek, yanlı ve etkin olmayan sonuçlar verecektir. Veri normal dağılımlı olmadığı için aritmetik ortalama artık temsil özelliğini kaybetmiştir. Bu nedenle, non-parametrik yöntemler olan grup farklılıklarının analizinde 2 grup için Mann-Whitney-U testi ile uygulanmıştır. Farkın kaynağı için ortalama sıra (mean rank) değerlerine bakılmıştır. Ortalama sıra değeri büyük olan farkın kaynağını oluşturmaktadır ve bu çalışmada koyu (bold) olarak tablo içinde gösterilmiştir.

Gurup farkl1lı̆̆ analizleri için hipotezler:

$\mathrm{H}_{0:}$ farkl111k yoktur.

$\mathrm{H}_{1:}$ farklılık vardır biçiminde kurulmuştur.

Tablo 10. Demografik Bilgiler Açısından Sisteme Dâhil Olma Durumu Açısından Farklılık Analiz Sonuçları

\begin{tabular}{|c|c|c|c|c|c|}
\hline Değişkenler & Grup & $\mathbf{N}$ & $\begin{array}{l}\text { Siraların Ortalaması } \\
\text { (Mean Rank) }\end{array}$ & $\begin{array}{c}\text { Mann- } \\
\text { Whitney-U }\end{array}$ & $\mathbf{P}$ \\
\hline \multirow[t]{3}{*}{ Cinsiyet } & Evet & 211 & 169.43 & \multirow{3}{*}{5.742} & \multirow{3}{*}{0.155} \\
\hline & Sistemden Ayrıldım & 139 & 184.72 & & \\
\hline & Toplam & 350 & & & \\
\hline \multirow[t]{3}{*}{ Yaş } & Evet & 211 & 184.76 & \multirow{3}{*}{9.641} & \multirow{3}{*}{$0.000^{*}$} \\
\hline & Sistemden Ayrıldım & 139 & 161.44 & & \\
\hline & Toplam & 350 & & & \\
\hline \multirow[t]{3}{*}{ Medenidu } & Evet & 211 & 168.34 & \multirow{3}{*}{10.885} & \multirow{3}{*}{$0.000 *$} \\
\hline & Sistemden Ayrıldım & 139 & 186.36 & & \\
\hline & Toplam & 350 & & & \\
\hline \multirow[t]{3}{*}{ Eğitimdü } & Evet & 211 & 190.92 & \multirow{3}{*}{11.463} & \multirow{3}{*}{$0.000 *$} \\
\hline & Sistemden Ayrıldım & 139 & 152.10 & & \\
\hline & Toplam & 350 & & & \\
\hline \multirow[t]{3}{*}{ Meslek } & Evet & 211 & 191.27 & \multirow{3}{*}{12.042} & \multirow{3}{*}{$0.000 *$} \\
\hline & Sistemden Ayrıldım & 139 & 151.57 & & \\
\hline & Toplam & 350 & & & \\
\hline \multirow[t]{3}{*}{ Gelirdüz } & Evet & 211 & 190.06 & \multirow{3}{*}{10.795} & \multirow{3}{*}{$0.000 *$} \\
\hline & Sistemden Ayrıldım & 139 & 153.40 & & \\
\hline & Toplam & 350 & & & \\
\hline \multirow[t]{3}{*}{ Asimetri } & Evet & 211 & 179.10 & \multirow{3}{*}{10.641} & \multirow{3}{*}{$0.000 *$} \\
\hline & Sistemden Ayrıldım & 139 & 177.62 & & \\
\hline & Toplam & 350 & & & \\
\hline
\end{tabular}

*0.05 için anlamlı farklılık 
BES'e dâhil olma durumu açısından sadece cinsiyet anlamlı farklılık göstermemiştir. Buna karşl1ık, medeni durum, eğitim düzeyi, meslek, gelir düzeyi ve asimetrik bilgi anlamlı farklılık göstermektedir. Farkın kaynağı için ortalama sıra değerlerine bakıldığında değeri yüksek olan farkı yaratmaktadır ve bold ile gösterilmiştir.

Sisteme dâhil olma durumuyla demografik değişkenlerin ilişkisi kategorik veri yapısında oldukları için Pearson ki-kare ilişki analizi ile belirlenmiştir. İlişki analizi için hipotezler; $H_{0:}$ İlişki yoktur $H_{1:}$ Illişki vardır biçimindedir.

Tablo 11. Demografik Değişkenler Ve Sisteme Dâhiliyet İlişki Sonuçları

\begin{tabular}{|c|c|c|c|c|}
\hline \multirow{2}{*}{\multicolumn{2}{|c|}{ Değişsenler }} & \multirow{2}{*}{\multicolumn{3}{|c|}{ Sisteme Dâhiliyet }} \\
\hline & & & \multirow{2}{*}{$\begin{array}{c}\begin{array}{c}\text { Sistemden } \\
\text { Ayrıldım }\end{array} \\
59\end{array}$} & \\
\hline \multirow[b]{2}{*}{ Cinsiyet } & Erkek & $\begin{array}{r}\text { Evet } \\
108\end{array}$ & & \multirow[b]{2}{*}{0,109} \\
\hline & Kadın & 103 & 80 & \\
\hline \multirow{6}{*}{ Yaş } & 18-24 Yaş & 26 & 23 & \multirow{6}{*}{$0,000^{*}$} \\
\hline & 25-30 Yaş & 65 & 41 & \\
\hline & 31-35 Yaş & 32 & 44 & \\
\hline & 36-40 Yaş & 44 & 11 & \\
\hline & 41-45 Yaş & 26 & 15 & \\
\hline & 46 ve üstü & 18 & 5 & \\
\hline \multirow{3}{*}{ Medeni Durum } & Evli & 111 & 59 & \multirow{3}{*}{$0,000^{*}$} \\
\hline & Bekâr & 88 & 70 & \\
\hline & Boşanmış & 12 & 10 & \\
\hline \multirow{7}{*}{ Eğitim Düzeyi } & İlkokul & 9 & 9 & \multirow{7}{*}{$0,002 *$} \\
\hline & Ortaokul & 5 & 8 & \\
\hline & Lise & 37 & 30 & \\
\hline & Ön lisans & 29 & 24 & \\
\hline & Lisans & 81 & 59 & \\
\hline & Yüksek lisans & 33 & 8 & \\
\hline & Doktora & 17 & 1 & \\
\hline \multirow{7}{*}{ Meslek } & İşçi & 36 & 51 & \multirow{7}{*}{$0,000^{*}$} \\
\hline & Öğretmen & 50 & 36 & \\
\hline & Memur & 14 & 1 & \\
\hline & Bankacı & 4 & 0 & \\
\hline & Sigortac1 & 4 & 0 & \\
\hline & Yönetici & 14 & 7 & \\
\hline & Diğer & 89 & 44 & \\
\hline \multirow{3}{*}{ Gelir Düzeyi } & $2000-2500$ & 48 & 52 & \multirow[b]{3}{*}{$0,001 *$} \\
\hline & $3000-3500$ & 59 & 41 & \\
\hline & $4000-4500$ & 41 & 22 & \\
\hline
\end{tabular}




\begin{tabular}{|l|l|l|l|l|}
\hline & 5000 ve üstü & 62 & 24 & \\
\hline \multirow{3}{*}{ Asimetrik bilgi } & Evet var & 153 & 98 & \multirow{2}{*}{$0,000^{*}$} \\
\cline { 2 - 5 } & Hayır yok & 58 & 41 & \\
\hline
\end{tabular}

*0.05 için anlamlı ilişki

Cinsiyet ve BES'e dâhil olma durumu anlamlı ilişkili değildir. Buna karşıllk medeni durum, eğitim düzeyi, meslek, gelir düzeyi ve asimetrik bilgi değişkenleri BES'e dâhil olma durumu ile anlamlı ilişkilidir.

Lojistik regresyon modelinde, $y$ iki kategorili bağımlı değişken ve $1 \mathrm{x}$ p boyutlu bağımsız değişken vektörü $x$ olmak üzere $x$ 'e göre $y^{\prime}$ nin koşullu ortalamasını gösteren $\pi(x)=E(y / x)$ niceliği kullanılır. Lojistik regresyon modeli,

$\pi(x)=\frac{e^{\beta_{0}+\beta_{1} x_{1}+\beta_{2} x_{2}+\ldots+\beta_{p} x_{p}}}{1+e^{\beta_{0}+\beta_{1} x_{1}+\beta_{2} x_{2}+\ldots+\beta_{p} x_{p}}}$

biçimin de yazılır. Burada $\beta_{0}$ sabit, $\beta_{p}$ regresyon katsayısı ve $\pi(x)$, bağımlı değişkenin $x$ 'e bağlı olarak 1'e eşit olması koşullu olasıı̆ı̆ıdır. Bu modelde $-\infty$ ile $+\infty$ arasında değer alabilen bağımsız değişkenlere dayanarak iki kategorili bağımlı değişkenin değerlerini tahmin etmek güçtür. Bu durumu ortadan kaldırmak için en iyi çözüm, bağımlı değişkenin olasılık değerinin - $\infty$ ile $+\infty$ arasında tanımlı hale getirilmesidir. Bu amaçla, $\pi(x)$ ' e dayanarak eşitlik 1'e lojit dönüşüm uygulanmasıyla,

$g(x)=\ln \left(\frac{\pi(x)}{1-\pi(x)}\right)=\beta_{0}+\beta_{1} x_{1}+\beta_{2} x_{2}+\ldots+\beta_{p} x_{p}$

modeli elde edilir. Lojit $\mathrm{g}(x), x^{\prime}$ in aralığına bağlı kalarak $-\infty$ ile $+\infty$ arasında değer alabilen doğrusal bir fonksiyondur.

Lojistik regresyonda, $\beta_{0}, \beta_{1}, \ldots, \beta_{p}$ katsayılarını tahmin etmede en çok olabilirlik yöntemi yaygın olarak kullanılmaktadır. İki kategorili bağımlı değişkenin i.nci birimin değeri $y_{i}$ olarak ele alındığında ve $x_{i}$ i.nci birim için bağımsız değiş̧ken vektöründeki değerlerini göstermek üzere $\left(x_{1 i}, x_{2 i}, \ldots, x_{p i}, y_{i}\right) \mathrm{n}$ tane bağımsız gözlem çiftinden oluşan bir örneklem olarak tanımlanabilir (i = 1, 2, .,n). Eğer bağımlı değişken $y, 0$ ya da 1 olarak kodlanmışsa $\pi(x)$, verilen $x$ için $y$ 'nin 1'e eşit olmasının koşullu olasılığını $(P(y=1 / x))$ verir. $1-\pi(x)$ ise, verilen $x$ için $y^{\prime}$ nin 0 'a eşit olmasının koşullu olasıllı̆̆ını $(P(y=0 / x))$ verir. Böylece $\left(x_{i}, y_{i}\right)$ çiftleri için, $y_{\mathrm{i}}=1$ 'in olabilirlik fonksiyonuna katkısı $\pi\left(x_{i}\right)$ ve $y_{\mathrm{i}}=$ 0'ın olabilirlik fonksiyonuna katkısı $1-\pi\left(x_{i}\right)$ ifadesine eşittir. Burada $\pi\left(x_{i}\right), x_{\mathrm{i}}$ ' de hesaplanan $\pi(x)$ olasılı̆̆ını tanımlar. $\left(x_{i}, y_{i}\right)$ çiftleri için olasılık ya da olabilirlik fonksiyonuna katkı, 
$\zeta\left(x_{i}\right)=\pi\left(x_{i}\right)^{y_{i}}\left[1-\pi\left(x_{i}\right)\right]^{1-y_{i}}$

eşitliği ile elde edilir. Gözlemlerin bağımsız olduğu varsayıldığı için olabilirlik fonksiyonu,

$$
I(\beta)=\prod_{i=1}^{n} \zeta\left(x_{i}\right)=\prod_{i=1}^{n} \pi\left(x_{i}\right)^{y_{i}}\left[1-\pi\left(x_{i}\right)\right]^{1-y_{i}}
$$

ile gösterilir ve en çok olabilirlik yöntemi bu eşitliği maksimum yapan $\beta$ vektörünün tahmin edilmesini sağlar.

Bu çalışmada BES'den ayrılan kişilere "0" kod ve sistemde kalan kişilere "1" kod verilerek bağımlı değişken olan sistemde kalma durumu değişkeni binary olarak oluşturulmuştur. Sistemde kalma durumu üzerinde etkili olduğu düşünülen asimetrik bilgi durumu ve bazı demografik değişkenler bağımsız değişken olarak modele dâhil edilmiştir. Bu analizde amaç, sistemden ayrılma durumu üzerinde risk oluşturan faktörleri belirlemektir.

Tablo 12. Lojistik Regresyon Tahmin Sonuçları

\begin{tabular}{|l|l|l|l|l|l|l|}
\hline Değişkenler & Katsayı & St. hata & Wald & s.d. & P & $\operatorname{Exp}(\mathbf{B})$ \\
\hline Asimetrik Bilgi & $-1,699$ &, 871 & 3,804 & 1 &, $051^{*}$ & 5,466 \\
Yaş & 1,247 &, 501 & 6,203 & 1 &, $013^{*}$ & 3,479 \\
Medeni Durum &, 209 &, 083 & 6,320 & 1 &, $011^{*}$ & 1,233 \\
Eğitim &, 153 &, 061 & 6,252 & 1 &, $012^{*}$ & 1,165 \\
Meslek & 1,309 &, 494 & 7,038 & 1 &, $008^{*}$ & 3,703 \\
Gelir & .432 & .205 & 4.436 & 1 & $.035^{*}$ & 1.540 \\
Sabit & 1,017 &, 157 & 41,734 & 1 &, $000^{*}$ &, 362 \\
\hline Lojistik Model İçin Anlamlılık Testleri: \\
Model Katsaylları için Omnibus Testi : Model için Ki-Kare Değeri $=478.32$, Prob $=0.000$ \\
-2 Log likelihood = 623,249; Cox \& Snell R Square= 0.763; Nagelkerke R Square $=0.795$ \\
Hosmer and Lemeshow Test: Ki-Kare Değeri= 5.773, Prob=0.504 > 0.05 \\
\hline
\end{tabular}

*0.05 için istatistik anlamlı değişken

Tahmin sonuçlarından görüleceği üzere ele alınan bağımsız değişkenler BES'e dâhil olma üzerinde istatistiki açıdan anlamlı ve önemlidir. Bu değişkenler için risk düzeylerine bakıldığında (exp B sütunu), asimetrik bilgi durumunun en yüksek exp B değerine sahip olarak $(5,466)$, BES'e dâhil olma durumu üzerinde yaklaşık 5.4 kat azaltıcı yönde risk unsuru olduğu belirlenmiştir. İkinci sırada meslek $(3,703)$ değeri ile yaklaşık 3.7 kat arttırıcı yönde BES için risk oluşturmaktadır. Üçüncü sırada yaş $(3,479)$ ile yaklaşık 3.4 kat arttırıcı yönde risk oluşturmaktadır. Dördüncü sırada $(1,540)$ değeri ile gelir, yaklaşık 1.5 kat arttırıcı yönde risk oluşturmaktadır. Beşinci sırada $(1,233)$ değeri ile medeni durum, yaklaşı 1.2 kat arttırıcı yönde risk oluşturmaktadır. Son olarak eğitim $(1,165)$ değeri ile yaklaşık 1.1 kat arttırıcı etki yaratmaktadır. 
Tablo 12'den de görülebilceği üzere, 5.466 değere sahip olan asimetrik bilgi piyasada bulunan aktörlerden birinin daha fazla bilgiye sahip olarak, karşı tarafı eksik ya da yanlış bilgilendirmesi sonucu ortaya çıkan bir problemdir. Bu durum tabii ki sisteme bakış açısını, sisteme duyulan güven gibi kavramları etkilemekte ve 5.4 kat azaltıcı bir risk unsuru olarak kendisini göstermektedir. Tablomuzda bulunan bir diğer değer olan meslek faktörü ise bireysel emeklilik sistemine olumlu açıdan etki etmekte ve kişilerin mesleği sisteme dâhil olma durumunu etkilemektedir. Mesleğin yanı sıra sisteme dâhil olma kararını olumlu yönde etkileyen diğer unsurlar ise sırasıyla kişilerin yaş, gelir durumları, medeni durumları ve eğitim durumları da olumlu yönde etki etmekte olan unsurlardandır.

Lojistik regresyon modelinin anlamlılığı için test sonuçlarını incelediğimizde ise, model katsay1ları için Omnibus Testi: Model için Ki-Kare Değeri $=478.32$, Prob $=0.000$ bulunmuş olup, katsayıların hepsi birlikte anlamlıdır. Lojistik regresyon tahmininde adımsal tahmin süreci izlenmiş ve her adımda -2 Log likelihood $=623.249$ değeri en düşük düzeyine, Cox \& Snell R Square $=0.763$ ve Nagelkerke R Square $=0.795$ değeri ise en yüksek değerine ulaşarak modelin anlamlılığı yükselmiştir. Modelin uygunluğu için temel bir test olan Hosmer ve Lemeshow Test: Ki-Kare Değeri= 5.773 , Prob=0.504 > 0.05 sonucuna ulaşılmıştır. Buna göre, testin anlamlılık seviyesi \%5'ten büyük olduğu için modelin uygun olduğu şeklindeki Ho reddedilemez, model üzerinden yapılacak yorumların güvenilir olduğu belirlenmiştir.

\section{SONUÇ}

BES 2003 y1lında uygulanmaya başlanmış olup günümüze kadar geçen süreçte pek çok gelişim ve ilerleme kaydetmiştir. Katılımcıların önemli bir kısmı, sisteme zorunlu olarak dâhil edilmeyi yanlış bulmuştur. Çalışmamıza katılanlardan 171 kişi sistem hakkında yeteri kadar bilgilendiriliyor musunuz soruna hayır seçeneği işaretlemişlerdir. Aynı şekilde asimetrik bilginin var olup olmadığını araştırdığımız sorumuza ise 251 katılımcımız evet mevcut diyerek asimetrik bilgi olduğunu söylemişlerdir. Sistemle alakalı yaşanan sıkıntıların nedenlerinden bir diğerinin ise müşteri danışmanlarının sürekli satış yapmaya çalışmaları olarak görülmüş ve bu şıkkı tercih eden katılımcı sayımız ise 172 kişidir.

Çalışmada yapılan analizler sonucunda, sistemden ayrılma ya da sisteme devam etme kararlarını etkileyen medeni durum, gelir düzeyi, eğitim seviyesi ve yaş gibi olguların yanı sıra kişilerin eksik ya da yanlış bilgilendirildiklerini düşünmeleri de bir faktördür. . Çalışmamıza katılan ve analize tabi olan 350 kişiden 153 kişi sistemde asimetrik bilginin varlı̆ğ konusunda hemfikir olmuşlardır.

Sisteme olan güvenin artırılması ve sistemde devamlılı̆̆ı sağlanabilmesi kişilerin doğru ve eksiksiz bilgilendirilmeleri ile elde edilebilecek bir durumdur. Sisteme dâhil olanlara ve ya sisteme henüz dâhil olmayan kişileri sistem hakkında doğru bilgiler verilmesi, sistemin emekliliğe maddi açıdan kaynak sağlamak, geleceği güvence altına almak, tasarruf yapmak ve bunun gibi pek çok avantajı 
eksiksiz bir şekilde anlatıldığı taktirde sistemin ilerleyen seneler içerisinde çok daha gelişeceğini insanların güvenleri sağlandığı müddetçe daha iyi bir ekonomik refaha ulaşılacağı düşünülmektedir.

\section{KAYNAKÇA}

Akerlof, A. G. (1970). "The Market for "Lemons": Quality Uncertainty and the Market Mechanism”, The Quarterly Journal of Economics, Vol. 84, No. 3, pp. 489-490.

EGM, Emeklilik Gözetim Merkezi, www.egm.org.tr

Fazzari, S. M. (1999). "Minsky and the Mainstream: Has Recent Research Rediscovered Financial Keynesianism?”, Working Paper No.278, The Jerome Levy Economics Institute.

Spence, M. (1973). "Job Market Signaling". Quarterly Journal of Economics. 87 (3): 355-374.

Stiglitz, E. J, Weiss, A. (1981). "Credit Rationing in Markets with Inperfect Information”, The American Economic Review, Vol. 71, No. 3, 1981, pp. 393-410.

Varian, R. H. (1993). Intermediate Microeconomics, Third Edition, W.W. Norton \& Company, 1993. 